\title{
Severe hyponatremia caused by secondary adrenal insufficiency in a patient with giant pituitary prolactinoma
}

\author{
Akimitsu Kobayashi $\cdot$ Yasushi Otsuka $\cdot$ Takeo Yoshizawa \\ Masuomi Tomita $\cdot$ Hideo Asada $\cdot$ Jun Ikeda $\cdot$ \\ Masato Saito $\cdot$ Katsuyoshi Tojo $\cdot$ Satoru Kuriyama $\cdot$ Tastuo Hosoya
}

Received: 26 July 2012/ Accepted: 7 January 2013/Published online: 9 February 2013

(C) Japanese Society of Nephrology 2013

\begin{abstract}
A 55-year-old-man was admitted to Saiseikai Central Hospital, Tokyo, Japan, complaining of nausea and appetite loss, and was found to have severe hyponatremia. Despite severe hyponatremia and plasma hypo-osmolarity, urinary sodium excretion was not reduced. A brain magnetic resonance imaging (MRI) scan revealed a giant pituitary prolactinoma, and endocrinological tests showed a markedly increased prolactin level. Despite the observation that the basal plasma ACTH level was normal, serum cortisol and urinary cortisol excretion levels were low. Rapid ACTH loading sufficiently stimulated an increase in serum cortisol levels, suggesting secondary adrenal insufficiency. Notably, loading of CRH induced a good ACTH response; however, the serum cortisol response remained low. In contrast, the continuous daily administration of exogenous ACTH
\end{abstract}

A. Kobayashi $\cdot$ Y. Otsuka $\cdot$ T. Yoshizawa $\cdot$ J. Ikeda

M. Saito $\cdot$ S. Kuriyama

Division of Nephrology, Saiseikai Central Hospital,

Tokyo, Japan

A. Kobayashi $(\bowtie) \cdot$ Y. Otsuka · T. Yoshizawa · S. Kuriyama ·

T. Hosoya

Division of Kidney and Hypertension, Department of Internal Medicine, Jikei University School of Medicine,

3-25-8 Nishi-shinbashi, Minato-ku, Tokyo 105-8471, Japan

e-mail: akimitsu@kk.iij4u.or.jp

M. Tomita

Division of Diabetes and Endocrinology, Saiseikai Central

Hospital, Tokyo, Japan

H. Asada

Department of Neurosurgery, Saiseikai Central Hospital,

Tokyo, Japan

K. Tojo

Division of Diabetes and Endocrinology, Department of Medicine, Jikei University School of Medicine, Tokyo, Japan dramatically increased serum cortisol levels. These discrepant responses may have been caused by the low biological activity of innate ACTH. Following partial resection of the prolactinoma, postoperative adjuvant therapy with cabergoline effectively reduced prolactin levels, but did not improve the hyponatremia. In contrast, hydrocortisone replacement therapy recovered the serum sodium level to the normal range. The present case is the first report describing a link between severe hyponatremia and biologically inactive circulating ACTH as a likely result of giant prolactinoma.

Keywords ACTH · Adrenal insufficiency ·

Hyponatremia $\cdot$ Prolactinoma

\section{Introduction}

Hyponatremia, a condition occurring when serum sodium concentrations drop below $135 \mathrm{mmol} / \mathrm{L}$, is one of the most common electrolyte disorders [1]. The correct and rapid diagnosis of hyponatremia is crucial because, at severe stages, hyponatremia can result in high morbidity and poor mortality in affected patients. Secondary adrenal insufficiency, one of the major causes of hypo-osmotic hyponatremia, results from hypothalamic or hypophyseal disorders [1]. Causes of pituitary adenoma-induced hyponatremia include hypopituitarism in association with concurrent dysfunction of the pituitary-adrenal axis [2] and the syndrome of inappropriate secretion of ADH (SIADH) [3-5]. Among the differential diagnoses of hyponatremia, several reports suggest that a pituitary gland corticotrophic adenoma may lead to impaired processing of mature ACTH. Reincke et al. [6] reported a case of a pituitary adenoma secreting adrenocorticotropin of high molecular weight without evidence of Cushing's disease, suggesting tumor- 
derived non-functional ACTH secretion. High molecular weight ACTH precursors, known as big ACTH, are characterized by low biological activity [7-9] and do not function as normal bioactive ACTH molecules. Preferential secretion of big-ACTH molecules can lead to impaired secretion of cortisol from the adrenal gland, possibly inducing severe hyponatremia.

In this communication, we describe a patient with severe hyponatremia complicated by a giant prolactinoma, whose etiology was attributable to biologically inactive endogenous ACTH. To our knowledge, the present case is the first to provide insight into the relationship between hyponatremia and secondary adrenal insufficiency due to low bioactive ACTH levels in association with a coincident pituitary prolactinoma.

\section{Case report}

A 55-year-old man with a 25-year history of diabetes mellitus developed nausea and a poor appetite lasting several days. In April 2011, due to worsening symptoms, he visited Saiseikai Central Hospital, Tokyo, Japan. Laboratory values revealed severe hyponatremia with a serum sodium of $119 \mathrm{mmol} / \mathrm{L}$, and the patient was admitted to the hospital to undergo further examination for a differential diagnosis. The patient had been taking three oral hypoglycemic agents, including metformin hydrochloride $(500 \mathrm{mg})$, glimepiride $(1.0 \mathrm{mg})$, and sitagliptin phosphate hydrate $(50 \mathrm{mg})$. A physical examination revealed the following: height $165 \mathrm{~cm}$, weight $68.8 \mathrm{~kg}$, blood pressure 135/76 $\mathrm{mmHg}$, and body temperature $36.7^{\circ} \mathrm{C}$. The patient was alert, without dry skin or tongue, no pretibial pitted edema, no galactorrhea, nor loss of libido. Neurological examination revealed no abnormal findings, including visual field.

\section{Laboratory data}

Table 1 shows the laboratory findings obtained upon patient admission. They reveal severe hypotonic hyponatremia characterized by the maintenance of urinary sodium excretion and high urinary osmolality. Control of diabetes was very poor, as shown by the high plasma glucose concentration and high $\mathrm{HbAlc}$ value.

\section{Endocrinological tests}

Table 2 reveals the basal levels of the various measured hormones. The serum prolactin (PRL) level was extremely elevated, and although the basal serum ACTH level remained within the normal range, the serum and urinary cortisol levels were extremely low. The ADH level was not reduced, in spite of the low plasma osmolarity. The circadian rhythm of ACTH and cortisol secretion was blunted (Table 3).

\section{Provocative tests}

\section{Rapid ACTH loading test}

Table 4 shows the result of the rapid ACTH test. The response of serum cortisol levels to exogenous ACTH was largely preserved (increase from 4.2 to $13.9 \mu \mathrm{g} / \mathrm{dL}$ ).

\section{CRH and GRH loading test}

To further evaluate the hypothalamic-pituitary-adrenal axis function, we performed a CRH and GRH loading test (Table 5). The response of plasma ACTH levels was moderately well preserved, although the serum cortisol level did not respond well to the CRH loading test (normal responses: plasma ACTH level $>2$ - to 4-fold increase, serum cortisol level $>20-25 \mu \mathrm{g} / \mathrm{dL}$ increase) [10], suggesting a substantial discrepancy between the plasma ACTH level and the serum cortisol level (Tables 4 and 5). These observations suggest the possible existence of nonfunctional ACTH. The response of GH to the GRH loading test was blunted.

Table 1 Laboratory data

\begin{tabular}{|c|c|c|c|c|c|c|c|}
\hline \multicolumn{2}{|l|}{$\mathrm{CBC}$} & \multicolumn{4}{|c|}{ Blood tests } & \multicolumn{2}{|c|}{ Urine tests } \\
\hline WBC & $4400 / \mu \mathrm{L}$ & AST & $35 \mathrm{mU} / \mathrm{mL}$ & $\mathrm{Na}$ & $119 \mathrm{mmol} / \mathrm{L}$ & $\mathrm{Na}$ & $110 \mathrm{mmol} / \mathrm{L}$ \\
\hline RBC & $3.96 \times 10^{6} / \mu \mathrm{L}$ & ALT & $31 \mathrm{mU} / \mathrm{mL}$ & $\mathrm{K}$ & $3.8 \mathrm{mmol} / \mathrm{L}$ & $\mathrm{K}$ & $52.8 \mathrm{mmol} / \mathrm{L}$ \\
\hline $\mathrm{Hb}$ & $12.9 \mathrm{~g} / \mathrm{dL}$ & LDH & $179 \mathrm{mU} / \mathrm{mL}$ & $\mathrm{Cl}$ & $89 \mathrm{mmol} / \mathrm{L}$ & Uosm & $838 \mathrm{mOsm} / \mathrm{kgH}_{2} \mathrm{O}$ \\
\hline $\mathrm{Ht}$ & $36.8 \%$ & UA & $2.2 \mathrm{mg} / \mathrm{dL}$ & PG & $145 \mathrm{mg} / \mathrm{dL}$ & & \\
\hline \multirow[t]{4}{*}{ PLT } & $17.9 \times 10^{4} / \mu \mathrm{L}$ & $\mathrm{Alb}$ & $3.8 \mathrm{~g} / \mathrm{dL}$ & $\mathrm{Hb}_{\mathrm{A} 1 \mathrm{C}}$ & $9.5 \%$ & & \\
\hline & & UN & $10.0 \mathrm{mg} / \mathrm{dL}$ & BNP & $32.7 \mathrm{pg} / \mathrm{mL}$ & & \\
\hline & & $\mathrm{Cr}$ & $0.5 \mathrm{mg} / \mathrm{dL}$ & CRP & $<0.3 \mathrm{mg} / \mathrm{dL}$ & & \\
\hline & & Posm & $254 \mathrm{mOsm} / \mathrm{k}$ & & & & \\
\hline
\end{tabular}

$C B C$ complete blood count, $P G$ plasma glucose concentration, $B N P$ B-type natriuretic peptide, Posm plasma osmolarity, Uosm urinary osmolarity 
Table 2 Endocrinological tests

\begin{tabular}{|c|c|c|c|}
\hline $\mathrm{TSH}$ & $2.58 \mu \mathrm{U} / \mathrm{mL}(0.3-4.5)$ & ACTH & $\begin{array}{r}28.4 \mathrm{pg} / \mathrm{mL} \\
(7.2-63.3)\end{array}$ \\
\hline FT3 & $2.06 \mathrm{pg} / \mathrm{mL}(2-4.5)$ & s-cortisol & $2.9 \mu \mathrm{g} / \mathrm{dL}(4.0-18.3)$ \\
\hline FT4 & $0.81 \mathrm{ng} / \mathrm{dL}(0.7-1.8)$ & u-cortisol & $\begin{array}{r}<10.0 \mu \mathrm{g} / \text { day } \\
(11.2-80.3)\end{array}$ \\
\hline PRL & $\begin{array}{c}15570 \mathrm{ng} / \mathrm{mL} \\
(4.3-13.6)\end{array}$ & PRA & $1.5 \mathrm{ng} / \mathrm{mL} / \mathrm{h}$ \\
\hline GH & $0.05 \mathrm{ng} / \mathrm{mL}(<0.17)$ & Aldosterone & $40.3 \mathrm{pg} / \mathrm{mL}$ \\
\hline LH & $\begin{array}{c}0.35 \mathrm{mIU} / \mathrm{mL} \\
\quad(0.79-5.72)\end{array}$ & $\mathrm{ADH}$ & $1.5 \mathrm{pg} / \mathrm{mL}(0.3-3.5)$ \\
\hline FSH & $\begin{array}{c}1.55 \mathrm{mIU} / \mathrm{mL} \\
(2.0-8.3)\end{array}$ & & \\
\hline
\end{tabular}

PRL prolactin, s-cortisol serum cortisol concentration, $u$-cortisol urinary cortisol concentration, $P R A$ plasma renin activity

Table 3 Circadian rhythm of ACTH and cortisol secretion

\begin{tabular}{lccr}
\hline & \multicolumn{3}{l}{ Time of the day } \\
\cline { 2 - 4 } & 0800 & 1600 & 2300 \\
\hline S-cortisol $(\mu \mathrm{g} / \mathrm{dl})$ & 3.0 & 1.6 & 2.5 \\
ACTH $(\mathrm{pg} / \mathrm{mL})$ & 48.7 & 34.2 & 25.2 \\
\hline
\end{tabular}

s-cortisol serum cortisol concentration

Table 4 Rapid ACTH loading test

\begin{tabular}{lc}
\hline Time $(\min )$ & s-cortisol $(\mu \mathrm{g} / \mathrm{dL})$ \\
\hline 0 & 4.2 \\
30 & 12.1 \\
60 & 13.9 \\
\hline
\end{tabular}

s-cortisol serum cortisol concentration

Table 5 CRH and GRH loading tests

\begin{tabular}{lcrcccc}
\hline & \multicolumn{6}{l}{ Time $(\mathrm{min})$} \\
\cline { 2 - 7 } & \multicolumn{1}{c}{0} & \multicolumn{1}{c}{15} & \multicolumn{1}{c}{30} & \multicolumn{1}{c}{60} & 90 & 120 \\
\hline ACTH $(\mathrm{pg} / \mathrm{mL})$ & 29.2 & 87.7 & 72.5 & 52.7 & 44.1 & 47.5 \\
s-cortisol $(\mu \mathrm{g} / \mathrm{dL})$ & $<1.0$ & 5.0 & 3.3 & 4.3 & 3.2 & 3.7 \\
GH $(\mathrm{ng} / \mathrm{ml})$ & 0.05 & & 1.25 & 1.87 & 1.26 & 0.63 \\
\hline
\end{tabular}

s-cortisol serum cortisol concentration

\section{Continuous exogenous ACTH loading test}

Continuous daily exposure to ACTH revealed a sharp elevation in both the serum and urinary cortisol levels (Table 6). During this daily continuous exogenous ACTH loading test, we observed that the serum sodium level increased to the normal range, accompanied by a rapid decrease in urinary sodium excretion. At this point, we suspected that the bioactivity of endogenous ACTH was
Table 6 Continuous ACTH loading test

\begin{tabular}{lrrlrr}
\hline & \multicolumn{6}{l}{ Time (days) } \\
\cline { 2 - 6 } & \multicolumn{1}{c}{-1} & \multicolumn{1}{c}{0} & 1 & \multicolumn{1}{l}{2} & \multicolumn{1}{c}{3} \\
\hline u-cortisol $(\mu \mathrm{g} / \mathrm{day})$ & $<10.0$ & $<8.0$ & 436 & 1,200 & 1,650 \\
s-cortisol $(\mu \mathrm{g} / \mathrm{dl})$ & 5.6 & 5.1 & 35.8 & 34 & 36.4 \\
\hline
\end{tabular}

s-cortisol serum cortisol concentration, $u$-cortisol urinary cortisol excretion

markedly blunted. Because of the extremely high serum PRL levels, we performed a brain magnetic resonance imaging (MRI) scan and found a pituitary tumor $44 \times 28 \times 29 \mathrm{~mm}$ in size (Fig. 1).

We hypothesized that the hyponatremia diagnosed in our patient might have been caused by the secondary adrenal insufficiency associated with the pituitary prolactinoma. Since the patient had been suffering from symptoms of severe hyponatremia, we initiated sodium supplementation therapy by infusing hypertonic saline $(3 \% \mathrm{NaCl})$, followed thereafter by water restriction. The patient responded well to the treatment and, as the serum sodium level returned to the normal range, his symptoms disappeared. One month following admission, in May 2011, we partially resected the giant pituitary tumor via transsphenoidal adenomectomy. Microscopic histological findings concerning the tumor were compatible with basophilic adenoma. Immunohistochemical staining for PRL was highly positive (Fig. 2a, b). These results confirmed that the giant pituitary tumor was compatible with prolactinoma. Furthermore, immunohistochemical staining for ACTH was positive in the residual normal tissue of the pituitary gland, but not in the tumor itself (Fig. 2c). Because the surgical resection was incomplete, the serum PRL level remained unchanged. The patient was given cabergoline $(0.50 \mathrm{mg} / \mathrm{week})$, and his serum PRL level decreased from 15570 to $60 \mathrm{ng} / \mathrm{mL}$. However, treatment with cabergoline did not normalize the patient's serum sodium level, and his symptoms recurred. Considering these clinical courses and the suspicion of secondary adrenal insufficiency, we initiated hormone replacement therapy with a daily dose of hydrocortisone $(15 \mathrm{mg})$. After hydrocortisone replacement therapy, the patient's FENa value, urinary sodium concentration, and urine osmolality were reduced (from 1.43 to $0.49 \%$, 110 to $30 \mathrm{mmol} / \mathrm{L}$, and 838 to $226 \mathrm{mOsm} / \mathrm{kgH}_{2} \mathrm{O}$, respectively).

The hormone replacement therapy was efficacious not only in restoring normal serum sodium levels, but also maintaining the patient in a symptom-free state without any clinical manifestations. The patient was discharged in July 2011. 
Fig. 1 Coronal (a) and sagittal (b) views of the brain magnetic resonance imaging (MRI). a A pituitary tumor of size $44 \times 28 \times 29 \mathrm{~mm}$ occupied the intrasellar space (arrows). b Compression of the pituitary stalk by the massive tumor (dashed circle)
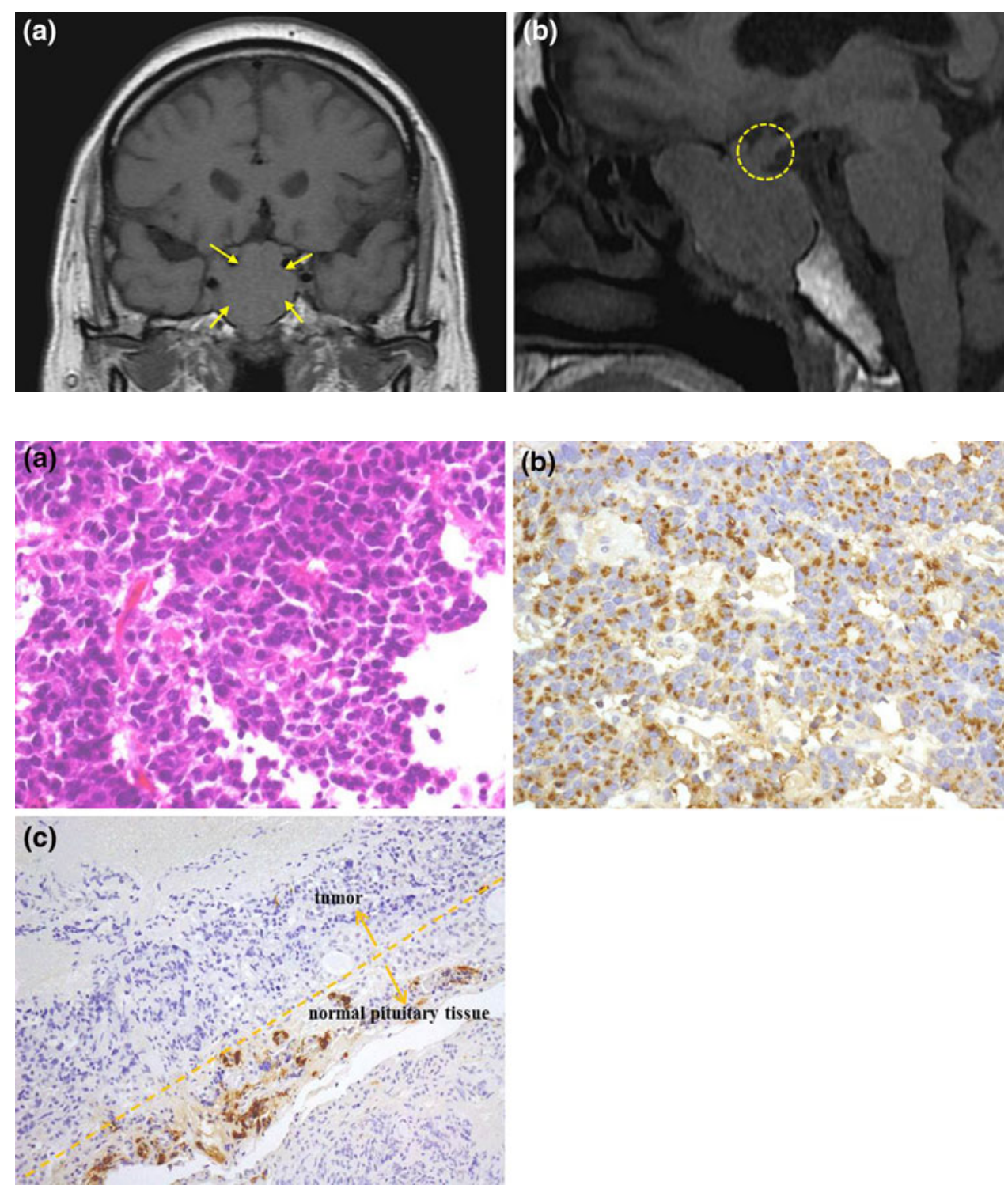

Fig. 2 Histopathological findings. a Basophilic small cells were abundant in the tumor tissue $(H \& E \times 400)$. b The immunohistochemical examination showed positive staining for prolactin, which was compatible with prolactinoma $(\times 400)$. c Immunohistochemical analysis showed ACTH staining in the residual normal tissue of the pituitary gland, but not in the tumor itself $(\times 200)$ moderately preserved. This discrepancy between plasma ACTH levels and the serum cortisol level may be due to biologically inactive endogenous ACTH molecules, since the ACTH loading test revealed normal cortisol responses.

Similar to our report, several case studies have described pituitary corticotrophic macroadenomas or ectopic ACTHproducing lung tumors without apparent Cushingoid features, which suggests a discrepancy between plasma ACTH levels and serum cortisol levels [6, 11, 12]. The mechanism underlying these dissociations may be related to the low biological activity of endogenous innate ACTH molecules.

Yalow and Berson [13], in 1971, were the first to report the presence of ACTH precursors and their size heterogeneity. Following their work, the large molecular ACTH precursor known as big ACTH has been detected in human plasma and in ACTH-producing thymoma extracts [8, 13]. 
Big-ACTH populations consisting of ACTH precursors, such as proopiomelanocortin (POMC) and pro-ACTH, are considered to result from the impaired processing of POMC to mature ACTH [14]. Although the immunoreactivity of big ACTH is indistinguishable from that of innate ACTH, their biochemical activities are very different: the activity of big ACTH is estimated to be $<4 \%$ of that of mature ACTH [9].

\section{The origin of inactive big ACTH}

Immunohistochemical analysis showed ACTH staining only in the residual tissue of the pituitary gland, and not in the tumor itself (Fig 2c). The mechanism by which putative big ACTH impairs pituitary function is largely unknown. However, one possible explanation is the qualitative or quantitative deficiency of the enzyme that facilitates the conversion of big ACTH to mature ACTH [12]. We could not confirm the presence of circulating big ACTH because the gel chromatographic technique required for its identification was not available. However, the results of our various endocrinological tests are highly suggestive of the existence of big-ACTH molecules.

Notably, our case is the first to raise questions about the relationship between the presence of a giant pituitary prolactinoma and secondary adrenal insufficiency, conceivably via a mechanism related to big ACTH. We speculate that the massive prolactinoma forced the pituitary stalk upward, affecting CRH release, which might induce bigACTH production. In addition, the circadian rhythm of ACTH secretion was disturbed because plasma ACTH levels in normal adults are usually $<20 \mathrm{pg} / \mathrm{mL}$ at 4 p.m. and $<5-10 \mathrm{pg} / \mathrm{mL}$ within $1 \mathrm{~h}$ after the usual time of falling asleep [15], suggesting at least partially abnormal pituitary function. Compression of the pituitary stalk may also have contributed to the deterioration of pituitary function itself through hypothalamic-pituitary-adrenal axis damage.

\section{Differential diagnosis of hyponatremia}

SIADH should be considered as one of the possible differential diagnoses of hyponatremia [3-5]. Previous reports have shown that local and mechanical stressors that compress the pituitary stalk influence the excessive release of $\mathrm{ADH}$. It is noteworthy that the plasma ADH level (1.5 pg/ $\mathrm{mL}$ ) was relatively high, despite the low plasma osmolarity (254 mOsm $/ \mathrm{kgH}_{2} \mathrm{O}$ ) (Tables 1 and 2). According to the criteria of Bartter and Schwartz [16], we could have diagnosed our case as SIADH. We initially treated the patient with sodium loading and water restriction due to the suspicion of SIADH associated with a pituitary tumor as the cause of the hyponatremia. As a result of our treatment, the intake of sodium exceeded urinary sodium excretion, which led to normalization of the serum sodium level, because salt excretion was not enhanced by increased salt loading during the period of amelioration (sodium intake $\sim 16 \mathrm{~g}$ /day, urinary sodium concentration $\sim 110-130$ $\mathrm{mmol} / \mathrm{L}$, urine volume $\sim 1.2-1.5 \mathrm{~L} /$ day).

A critical issue for the differential diagnosis is to assess the presence or absence of the impairment of free-water excretion. Although typical physical signs and symptoms suggesting an increase in extracellular fluid (ECF) volume and urine volume depletion were absent, a slight elevation of BNP and low level of uric acid are suggestive when concomitant with mild impairment of free-water excretion. Cortisol deficiency is well known to lead to failure to suppress ADH in hypo-osmolarity or hypotonicity. The unsuppressed excretion of ADH due to cortisol insufficiency might induce SIADH-like conditions and may be the reason why water restriction therapy was effective in our case. Regrettably, we did not measure the ADH level after the therapy. However, our clinical observation that, after hydrocortisone replacement therapy, the FENa and urinary sodium concentration were reduced (from 1.43 to 0.49 and 110 to $30 \mathrm{mmol} / \mathrm{L}$, respectively) and that the serum sodium level was rendered normal indicated that the main cause of the hyponatremia was adrenal insufficiency.

In conclusion, we have described a patient with severe hyponatremia that was complicated by a giant pituitary prolactinoma. The pathogenesis of hyponatremia may, at least in part, be explained by secondary adrenal insufficiency related to inactive big ACTH molecules. Further clinical description and relevant basic experiments are warranted in the future.

Acknowledgments We thank Kiyoshi Mukai M.D., Division of Pathology, Saiseikai Central Hospital, for his technical expertise in the preparation of our immunohistochemical examinations. We also thank Hiroshi Hayakawa M.D., Division of Kidney and Hypertension, Department of Internal Medicine, Jikei University School of Medicine, for the critical advice about the assessment of this case.

Conflict of interest No conflict of interest is declared.

\section{References}

1. Schrier RW, Bansal S. Diagnosis and management of hyponatremia in acute illness. Curr Opin Crit Care. 2008;14:627-34.

2. Foppiani L, Ruelle A, Quilici P, Del Monte P. Hypopituitarism in the elderly: two case-reports with heterogeneous presentation. Aging Clin Exp Res. 2009;21:76-81.

3. Saito T, Watanabe $\mathrm{Y}$, Yuzawa $\mathrm{M}$, et al. SIADH is only an atypical clinical feature in a patient with prolactinoma. Intern Med. 2007;46:653-6.

4. Greiss KC, Moses AM, Krieger DT. Pituitary adenoma associated with inappropriate antidiuretic hormone secretion. Acta Endocrinol (Copenh). 1974;76:59-66. 
5. Kanda M, Omori Y, Shinoda S, et al. SIADH closely associated with non-functioning pituitary adenoma. Endocr J. 2004;51(4): 435-8.

6. Reincke M, Allolio B, Saeger W, Kaulen D, Winkelmann W. A pituitary adenoma secreting high molecular weight adrenocorticotropin without evidence of Cushing's disease. J Clin Endocrinol Metab. 1987;65:1296-300.

7. Stewart PM, Gibson S, Crosby SR, et al. ACTH precursors characterize the ectopic ACTH syndrome. Clin Endocrinol (Oxf). 1994;40:199-204.

8. Yalow RS, Berson SA. Characteristics of "big ACTH" in human plasma and pituitary extracts. $J$ Clin Endocrinol Metab. 1973;36:415-23.

9. Gewirtz G, Schneider B, Krieger DT, Yalow RS. Big ACTH: conversion to biologically active ACTH by trypsin. J Clin Endocrinol Metab. 1974;38:227-30.

10. Longo D, Fauci A, Kasper D, Hauser S, Jameson J, Loscalzo J. Harrison's principles of internal medicine. 18th ed. New York: McGraw-Hill; 2008.
11. Peacock I, Jeffcoate WJ. Corticotrophic macroadenoma of the pituitary associated with hypoadrenalism. Clin Endocrinol (Oxf). 1997;46:765-8.

12. Gewirtz G, Yalow RS. Ectopic ACTH production in carcinoma of the lung. J Clin Invest. 1974;53:1022-32.

13. Yalow RS, Berson SA. Size heterogeneity of immunoreactive human ACTH in plasma and in extracts of pituitary glands and ACTH-producing thymoma. Biochem Biophys Res Commun. 1971;44:439-45.

14. Gibson S, Ray DW, Crosby SR, et al. Impaired processing of proopiomelanocortin in corticotroph macroadenomas. J Clin Endocrinol Metab. 1996;81:497-502.

15. Reed Larsen P, Kronenberg HM, Melmed S, Polonsky KS. Williams textbook of endocrinology. 10th ed. Philadelphia: Saunders; 2002.

16. Bartter FC, Schwartz WB. The syndrome of inappropriate secretion of antidiuretic hormone. Am J Med. 1967;42:790-806. 